\title{
əImproved SSM/I Thin Ice Algorithm with Ice Type Discrimination in Coastal Polynyas
}

\author{
HARUHIKo KASHIWASE, ${ }^{\mathrm{a}, \mathrm{b}}$ KAy I. OHSHIMA, ${ }^{\mathrm{c}, \mathrm{d}}$ KAZUKI NAKATA, ${ }^{\mathrm{c}}$ AND TAKESHI TAMURA ${ }^{\mathrm{b}, \mathrm{e}}$

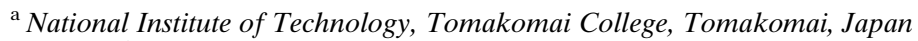 \\ ${ }^{\mathrm{b}}$ National Institute of Polar Research, Tachikawa, Japan \\ ${ }^{\mathrm{c}}$ Institute of Low Temperature Science, Hokkaido University, Sapporo, Japan \\ ${ }^{\mathrm{d}}$ Arctic Research Center, Hokkaido University, Sapporo, Japan \\ e SOKENDAI, Graduate University for Advanced Studies, Tachikawa, Japan
}

(Manuscript received 1 September 2020, in final form 8 December 2020)

\begin{abstract}
Long-term quantification of sea ice production in coastal polynyas (thin sea ice areas) is an important issue to understand the global overturning circulation and its changes. The Special Sensor Microwave Imager (SSM/I), which has nearly 30 years of observation, is a powerful tool for that purpose owing to its ability to detect thin ice areas. However, previous SSM/I thin ice thickness algorithms differ between regions, probably due to the difference in dominant type of thin sea ice in each region. In this study, we developed an SSM/I thin ice thickness algorithm that accounts for three types of thin sea ice (active frazil, thin solid ice, and a mixture of two types), using the polarization and gradient ratios. The algorithm is based on comparison with the ice thickness derived from the Moderate Resolution Imaging Spectroradiometer (MODIS) for 22 polynya events off the Ross Ice Shelf, off Cape Darnley, and off the Ronne Ice Shelf in the Southern Ocean. The algorithm can properly discriminate the ice type in coastal polynyas and estimate the thickness of thin sea ice $(\leq 20 \mathrm{~cm})$ with an error range of less than $6 \mathrm{~cm}$. We also confirmed that the algorithm can be applied to other passive microwave radiometers with higher spatial resolution to obtain more accurate and detailed distributions of ice type and thickness. The validation of this algorithm in the Arctic Ocean suggests its applicability to the global oceans.
\end{abstract}

KEYWORDS: Sea ice; Ice thickness; Algorithms; Microwave observations; Remote sensing; Satellite observations

\section{Introduction}

Sea ice production in coastal polynyas plays a key role in the global climate system. A coastal polynya is an area of thin sea ice/open water that is $10-100 \mathrm{~km}$ in width along a coastline, maintained by offshore-ward winds and ocean currents (Morales Maqueda et al. 2004; Barber and Massom 2007). In polar oceans, sea ice acts as a thermal barrier between the ocean and the atmosphere. However, in coastal polynyas, heat loss from the ocean to the atmosphere is approximately two orders of magnitude larger than that in the surrounding areas of thicker sea ice (Maykut 1978). Therefore, active sea ice production occurs in coastal polynyas within sea ice areas. When seawater freezes, high-salt water (brine) is rejected from sea ice, forming cold dense shelf water (DSW). This DSW drives the meridional overturning circulation of the global ocean by sinking into the intermediate/deep layer, and it contributes to the formation of Antarctic Bottom Water (AABW) (Orsi et al. 1999; Ohshima et al. 2013) and North Pacific Intermediate Water (NPIW) (Warner et al. 1996; Shcherbina et al. 2003). DSW formation due to active ice production also affects the maintenance of the cold halocline layer in the Arctic Ocean (Cavalieri and Martin 1994). Accumulated hydrographic observations have revealed a significant warming in AABW in recent years (Purkey and Johnson

\footnotetext{
D Denotes content that is immediately available upon publication as open access.
}

Corresponding author: Haruhiko Kashiwase, kashiwase@ tomakomai-ct.ac.jp
2013; Rhein et al. 2013). Also, warming trends in NPIW and its upstream Okhotsk Sea Intermediate Water have been evident over the past 50 years (Nakanowatari et al. 2007). These findings suggest a weakening of the overturning circulation, and hence decreasing sea ice production in coastal polynyas. However, accurate long-term estimation of sea ice production has not been achieved yet, and therefore, it remains unclear whether sea ice production in coastal polynyas is actually decreasing or not.

Several previous studies have quantified the sea ice production in coastal polynyas, mainly by combining satellitebased passive microwave radiometers with a heat budget analysis. The spatial resolution of passive microwave radiometers (from 6 to $50 \mathrm{~km}$, depending on sensor and frequency) is much coarser than that of infrared radiometers $(\sim 1 \mathrm{~km})$. However, passive microwave radiometers are useful for tracking spatially and temporally varying coastal polynyas because they enable daily observation of the global oceans regardless of weather conditions. In areas of thin sea ice (typically, thickness $\leq 20 \mathrm{~cm}$ ), the polarization ratio (PR) of vertically and horizontally polarized brightness temperatures derived from passive microwave radiometers is related to the thickness of sea ice. The PR value decreases as sea ice becomes thicker (Steffen and Maslanik 1988; Steffen 1991; Tateyama et al. 2002). Note that this PR-thickness relationship actually reflects an indirect correspondence between microwave radiation at the top of the sea ice and the brine volume within the ice surface layer, which is correlated with the physical thickness of sea ice (Cox and Weeks 1974; Grenfell and Comiso 1986; Hwang et al. 2007; Naoki et al. 2008). Based on this characteristic, algorithms for classifying sea ice as new ice, young ice, and first-year ice were developed using the PR value and the gradient ratio (GR) of brightness temperatures at 
different frequencies derived from the Special Sensor Microwave Imager (SSM/I) in the Bering Sea (Cavalieri 1994) and the Sea of Okhotsk (Martin et al. 1998; Kimura and Wakatsuchi 1999; Tateyama et al. 2000). Ohshima et al. (2003) later acquired the first quantification of sea ice production in the Okhotsk coastal polynyas by heat budget analysis, assuming a uniform sea ice thickness of $5 \mathrm{~cm}$ for new ice and $20 \mathrm{~cm}$ for young ice.

Accurate quantification of sea ice production requires detailed information on sea ice thickness in the coastal polynya. Martin et al. (2004) compared the SSM/I PR values [strictly $R$ values in their study; $R=(1+\mathrm{PR}) /(1-\mathrm{PR})]$ with ice thickness obtained from a heat budget analysis (Yu and Rothrock 1996; Drucker et al. 2003) using ice surface data from the Advanced Very High Resolution Radiometer (AVHRR), and developed a thin ice thickness algorithm for the Chukchi coastal polynya in the Arctic Ocean. Based on such thin ice thickness (TIT) algorithms using SSM/I, the Advanced Microwave Scanning Radiometer EOS (AMSR-E), or the Advanced Microwave Scanning Radiometer 2 (AMSR2), sea ice thicknesses up to $20 \mathrm{~cm}$ were derived, and sea ice productions were quantified through heat budget analyses in the Southern Ocean (Tamura et al. 2007, 2008, 2016; Comiso et al. 2011; Nihashi and Ohshima 2015; Nihashi et al. 2017), the Arctic Ocean (Tamura and Ohshima 2011; Iwamoto et al. 2013, 2014), the Sea of Okhotsk (Nihashi et al. 2009; Kashiwase et al. 2014), and the Bering Sea (Ohshima et al. 2020). In addition, finer mappings of thin ice thickness and sea ice production were recently obtained using clear-sky infrared data from the Moderate Resolution Imaging Spectroradiometer (MODIS) in the Southern Ocean (Paul et al. 2015) and the Arctic Ocean (Preußer et al. 2016).

Recently, the accuracy of TIT algorithms has been improved by considering the type of thin sea ice in the coastal polynya (Nakata et al. 2019). Sea ice in the coastal polynya can be divided into two types: thin solid ice and active frazil. Thin solid ice, including nilas and undeformed level ice, forms under relatively calm conditions. Active frazil, a mixture of open water and frazil ice with minimal thickness, forms under strong wind conditions. Nakata et al. (2019) investigated the relationships between AMSR-E PR values and MODIS thicknesses, taking into account the ice type classified from the backscatter images of Advanced Synthetic Aperture Radar (ASAR), and showed that the thickness of active frazil is much smaller than that of thin solid ice with the same PR value. In addition, Nakata et al. (2019) developed a method for classifying the type of thin sea ice from the AMSR-E PR and GR values, thereby improved the TIT algorithm.

To quantify long-term variations in sea ice production, the use of SSM/I [and its successor, the Special Sensor Microwave Imager/Sounder (SSMIS)] is inevitable. In the past, SSM/I TIT algorithms were developed for the Southern Ocean (Tamura et al. 2007), the Arctic Ocean (Tamura and Ohshima 2011), and the Sea of Okhotsk (Kashiwase et al. 2014), and sea ice production mappings were provided after 1992. However, these previous studies used different PR-thickness relationships to estimate thin ice thickness. Nakata et al. (2019) hypothesized that such differences are due to the dominant type of thin sea ice varying between target regions, and thus suggested the feasibility of a global algorithm that takes ice type into account. This hypothesis was partly verified by a direct comparison of AMSR-E and sea ice thickness data derived from a mooring observation off Sakhalin in

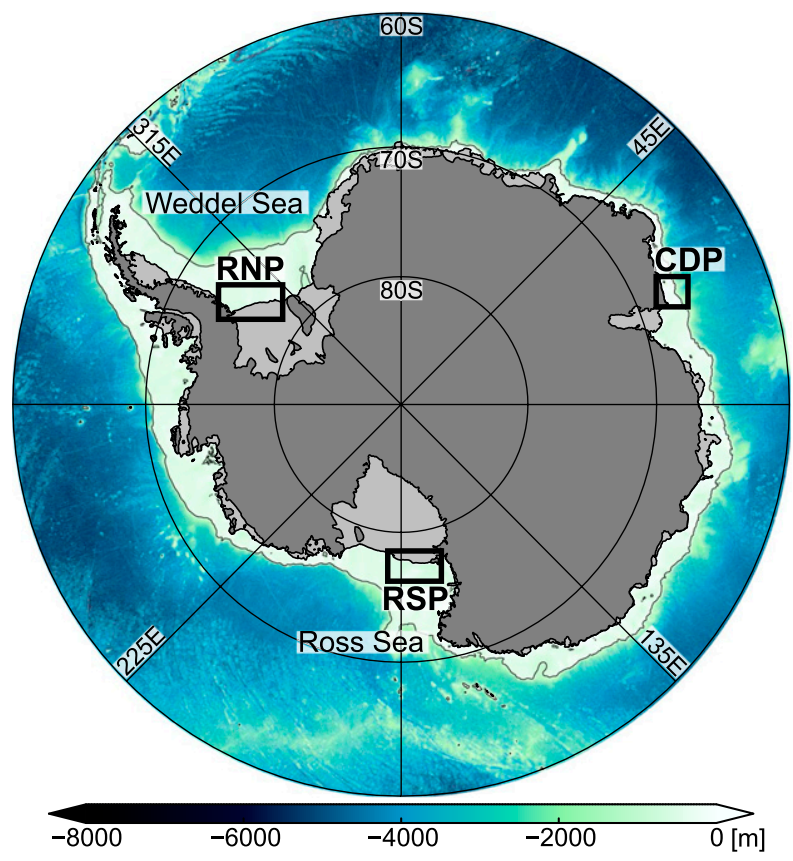

FIG. 1. Map of the Southern Ocean with the bathymetric chart from IBCSO, version 1.0 (Arndt et al. 2013). The gray and light gray areas indicate land and ice shelves, respectively. Thin contour indicates the $1000 \mathrm{~m}$ isobath. Rectangles indicate the coastal polynyas: Ross Ice Shelf polynya (RSP), Cape Darnley polynya (CDP), and Ronne Ice Shelf polynya (RNP), which were used for development of the thin ice thickness algorithm.

the Sea of Okhotsk in winter 2003 (Kashiwase et al. 2019). The direct comparison showed a PR-thickness relationship similar to that derived from the Antarctic coastal polynyas for thin solid ice, as well as a tendency for a mixture with active frazil to have a smaller thickness than purely thin solid ice with the same PR value. The use of SSM/I with coarser spatial resolution results in a large number of pixels with a mixture of active frazil and thin solid ice even in a relatively large coastal polynya. Therefore, incorporation of a mixed ice category into the algorithm is necessary.

In this study, we develop a SSM/I TIT algorithm that incorporates a method to classify three types of thin sea ice: active frazil, thin solid ice, and a mixture of the two (mixed ice) after 1992, when high-frequency ( 85 or $91 \mathrm{GHz}$ ) channel data are available. For development of the algorithm, we use 22 cases within Antarctic coastal polynyas (off the Ross Ice Shelf, off Cape Darnley, and off the Ronne Ice Shelf, as shown in Fig. 1). In addition, we validate our new algorithm using 26 cases from three coastal polynyas and a marginal ice zone in the Arctic Ocean, which were used for development and validation of the previous algorithm for the Arctic Ocean (Iwamoto et al. 2013, 2014). Finally, we discuss the global applicability of the algorithm.

\section{Data and methods}

\section{a. Passive microwave radiometers}

In this study, we used the DMSP SSM/I-SSMIS Pathfinder daily Equal Area Scalable Earth Grid (EASE-Grid) brightness 
TABLE 1. Summary of intercomparison of brightness temperatures between SSM/I-SSMIS and AMSR-E for the Antarctic sea ice zone. Slope and intercept are the coefficients of linear least squares fitting of $y$ on $x$, and RMSD is the root-mean-square deviation of $x$ with respect to $y$.

\begin{tabular}{cccc}
\hline \hline Channel & Slope & Intercept & RMSD $(\mathrm{K})$ \\
\hline & F11-SSM/I $(x)$ vs F13-SSM/I $(y)$ & \\
$19 \mathrm{~V}$ & 1.01 & -1.58 & 3.56 \\
$37 \mathrm{~V}$ & 1.01 & -2.22 & 2.96 \\
$37 \mathrm{H}$ & 1.00 & 0.26 & 5.72 \\
$85 \mathrm{~V}$ & 0.99 & 2.10 & 3.18 \\
& & & \\
$19 \mathrm{~V}$ & F13-SSM/I $(x)$ vs & AMSR-E $(y)$ & 5.11 \\
$37 \mathrm{~V}$ & 0.99 & 2.11 & 5.11 \\
$37 \mathrm{H}$ & 0.96 & 12.05 & 10.46 \\
$85 \mathrm{~V}$ & 1.04 & -9.19 & 6.80 \\
& 1.05 & -7.65 & \\
$19 \mathrm{~V}$ & F17-SSMIS $(x)$ vs AMSR-E $(y)$ & 4.68 \\
$37 \mathrm{~V}$ & 1.03 & -4.89 & 4.59 \\
$37 \mathrm{H}$ & 0.97 & 7.42 & 9.60 \\
$91 \mathrm{~V}$ & 1.03 & -7.74 & 6.33 \\
\hline
\end{tabular}

temperatures, version 2 (Armstrong et al. 1994), at vertically and horizontally polarized 19, 37, and 85 (91 for F17-SSMIS) $\mathrm{GHz}$ channels for the development of a TIT algorithm. This dataset contains twice daily (ascending and descending orbits) brightness temperatures interpolated onto the EASE-Grid with a spatial resolution of $25 \mathrm{~km} \times 25 \mathrm{~km}$, provided by the National Snow and Ice Data Center (NSIDC). As a preliminary treatment, SSM/I brightness temperatures were compared with AMSR-E brightness temperatures (Knowles et al. 2006) over the Antarctic sea ice region and corrected to values corresponding to AMSR-E observations at 18,36 , and $89 \mathrm{GHz}$ channels. Table 1 summarizes the details of comparisons and corrections. In this paper, both the SSM/I $85 \mathrm{GHz}$ and the SSMIS $91 \mathrm{GHz}$ channels are referred to as the $85 \mathrm{GHz}$ channel. Using the corrected brightness temperatures (TBs), PR and GR values were calculated as follows:

$$
\begin{aligned}
\mathrm{PR}_{37} & =\frac{\mathrm{TB}_{37 \mathrm{~V}}-\mathrm{TB}_{37 \mathrm{H}}}{\mathrm{TB}_{37 \mathrm{~V}}+\mathrm{TB}_{37 \mathrm{H}}}, \\
\mathrm{GR}_{8519 \mathrm{~V}} & =\frac{\mathrm{TB}_{85 \mathrm{~V}}-\mathrm{TB}_{19 \mathrm{~V}}}{\mathrm{~TB}_{85 \mathrm{~V}}+\mathrm{TB}_{19 \mathrm{~V}}} .
\end{aligned}
$$

\section{b. Thermal ice thickness from MODIS}

As comparison data for the development of TIT algorithm, we used the thermal infrared images from Terra and Aqua MODIS at 31 and 32 channels (MODIS Characterization Support Team 2017a,b), provided by NASA's Level 1 and Atmosphere Archive and Distribution System website (LAADS web; http://ladsweb.nascom.nasa.gov). The spatial resolution of this dataset is $\sim 1 \mathrm{~km}$. Ice surface temperature was obtained from the thermal infrared images using the method of Key et al. (1997). Then heat budget analysis was carried out using the ice surface temperature and near-surface atmospheric data, and a hypothetical thickness satisfying the thermal balance at the sea ice surface
TABLE 2. Location, date, and time of polynya events used in the development of SSM/I thin ice thickness algorithm. The abbreviations for polynya are as follows: Ross Ice Shelf polynya (RSP), Cape Darnley polynya (CDP), and Ronne Ice Shelf polynya (RNP).

\begin{tabular}{cccccc}
\hline \hline & & & \multicolumn{3}{c}{ Time (UTC) } \\
\cline { 3 - 5 } Case & Polynya & Date & ASAR & SSM/I & MODIS \\
\hline 1 & RSP & 21 Jul 2006 & 1825 & 1806 & 1915 \\
2 & & 14 Aug 2006 & 1730 & 1730 & 1825 \\
3 & & 11 Sep 2006 & 1750 & 1730 & 1850 \\
4 & & 26 Apr 2008 & 1534 & 1721 & - \\
5 & & 23 Apr 2009 & 1737 & 1651 & - \\
6 & & 30 Apr 2009 & 1716 & 1703 & 1705 \\
7 & & 3 Jul 2009 & 1703 & 1701 & - \\
8 & CDP & 3 Jul 2006 & 1938 & 2406 & 1950 \\
9 & & 2 Sep 2008 & 1946 & 1354 & 1905 \\
10 & & 25 May 2009 & 2730 & 2334 & 2645 \\
11 & & 16 Sep 2009 & 1934 & 2306 & - \\
12 & & 7 Oct 2009 & 0317 & 1345 & - \\
13 & & 13 Oct 2009 & 0328 & 0022 & - \\
14 & & 9 Jul 2010 & 1931 & 2254 & - \\
15 & & 15 Jul 2010 & 1943 & 2319 & - \\
16 & RNP & 17 May 2006 & 0547 & 0812 & - \\
17 & & 14 Jun 2006 & 0606 & 0818 & 0550 \\
18 & & 15 Jun 2006 & 0535 & 0948 & 0455 \\
19 & & 9 Aug 2006 & 0507 & 0830 & - \\
20 & & 10 Aug 2006 & 0615 & 0812 & 0720 \\
21 & & 22 Jul 2009 & 0522 & 0753 & 0605 \\
22 & & 26 Jul 2009 & 0457 & 0702 & - \\
\hline
\end{tabular}

was calculated. Such a hypothetical thickness, referred to as thermal ice thickness, coincides with the physical ice thickness for a uniform sea ice field. While for a nonuniform sea ice field, this thickness is smaller than the average for physical ice thickness because of the nonlinear relationship between thickness and the heat insulating effect of sea ice (Maykut 1978). As shown by a comparison of mooring-based ice thickness and AMSR-E data, thermal ice thickness can be estimated from the PR value regardless of a uniform or nonuniform sea ice field (Kashiwase et al. 2019). Moreover, thermal ice thickness is useful for quantifying the heat budget and sea ice production in the coastal polynya. Despite the relatively coarse spatial resolution, the thermal ice thickness from AMSR-E can provide an estimation of sea ice production with similar accuracy to higher-spatial-resolution data such as mooring observations (Fukamachi et al. 2017) and MODIS (Preußer et al. 2019). The algorithm developed in this study is also for deriving such thermal ice thickness.

The MODIS thermal ice thickness can be calculated through the following procedures. Net heat flux between the sea ice and the atmosphere $(\mathrm{FN})$ is calculated as the sum of shortwave radiation (SW), longwave radiation (LW), and sensible and latent heat fluxes (SE and LA, respectively), as the following equation:

$$
\mathrm{FN}=\left(1-\alpha_{i}\right) \mathrm{SW}+\mathrm{LW}+\mathrm{SE}+\mathrm{LA},
$$

where $\alpha_{i}$ is the albedo of sea ice surface. Since only nighttime cases are used in this study, shortwave radiation with relatively 

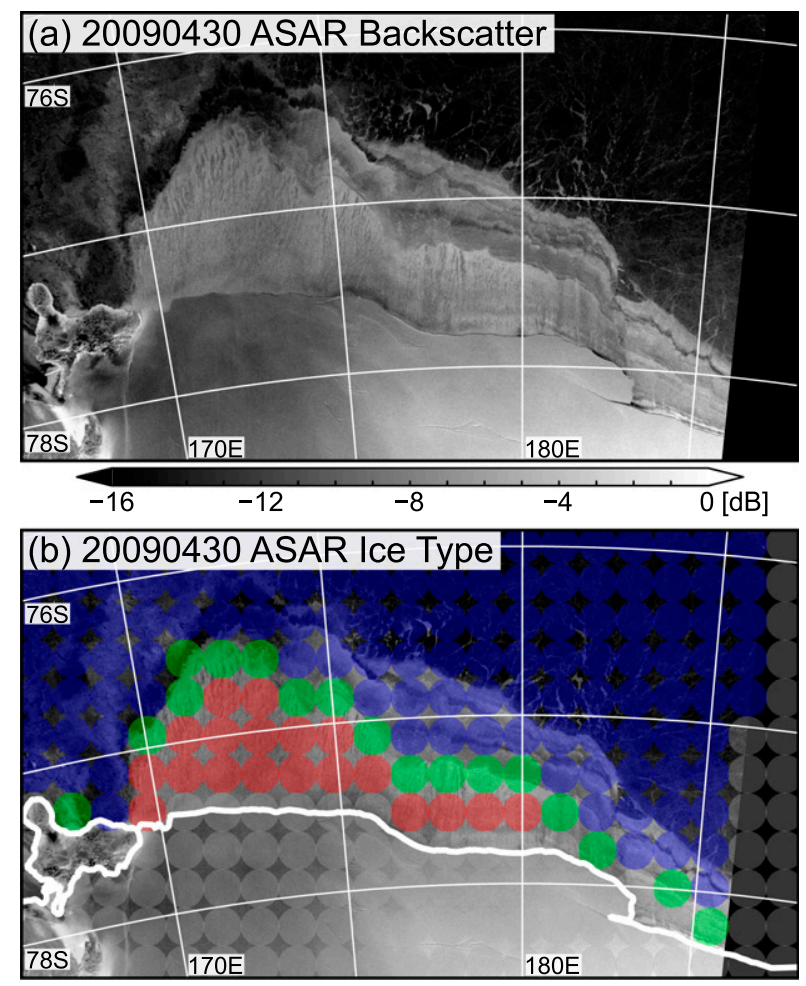

Active Frazil Mixed Ice Solid Ice

FIG. 2. (a) The backscatter image of ASAR off the Ross Ice Shelf on 30 Apr 2009 and (b) the result of visual classification of ice types on the $25 \mathrm{~km} \times 25 \mathrm{~km}$ EASE-Grid, superimposed on the ASAR image. Active frazil, mixed ice, and solid ice are shown by red, green, and blue colors, respectively.

high uncertainty can be regarded as zero. The calculation of each heat component, which is a function of ice surface temperature, follows previous studies (e.g., Nihashi and Ohshima 2015); longwave radiation was calculated from the empirical formula (König-Langlo and Augstein 1994); and turbulent heat fluxes were calculated from the bulk formulas (Maykut and Perovich 1987) using bulk transfer coefficients that take into account the stability of the atmospheric surface layer (Kondo 1975). When sea ice thickness is small, thermal inertia can be ignored and thus a linear temperature distribution inside the sea ice can be assumed (Ohshima et al. 2003). Therefore, net heat flux on sea ice surface balances with the conductive heat flux through the ice (FC). Once FC is determined, the thermal ice thickness $\left(h_{t}\right)$ can be calculated with the following equation:

$$
h_{t}=\frac{k_{i}\left(T_{\mathrm{surf}}-T_{\mathrm{bttm}}\right)}{\mathrm{FC}},
$$

where $k_{i}=2.03 \mathrm{~W} \mathrm{~m}^{-1} \mathrm{~K}^{-1}$ is the bulk heat transfer coefficient, and $T_{\text {surf }}$ and $T_{\mathrm{bttm}}$ are surface and bottom temperatures of sea ice, respectively. Although $k_{i}$ is a parameter that varies with conditions of sea ice deformation and surface snow cover (Lüpkes and Gryanik 2015), we regarded it as a constant value because this study focuses on thin sea ice that is formed in
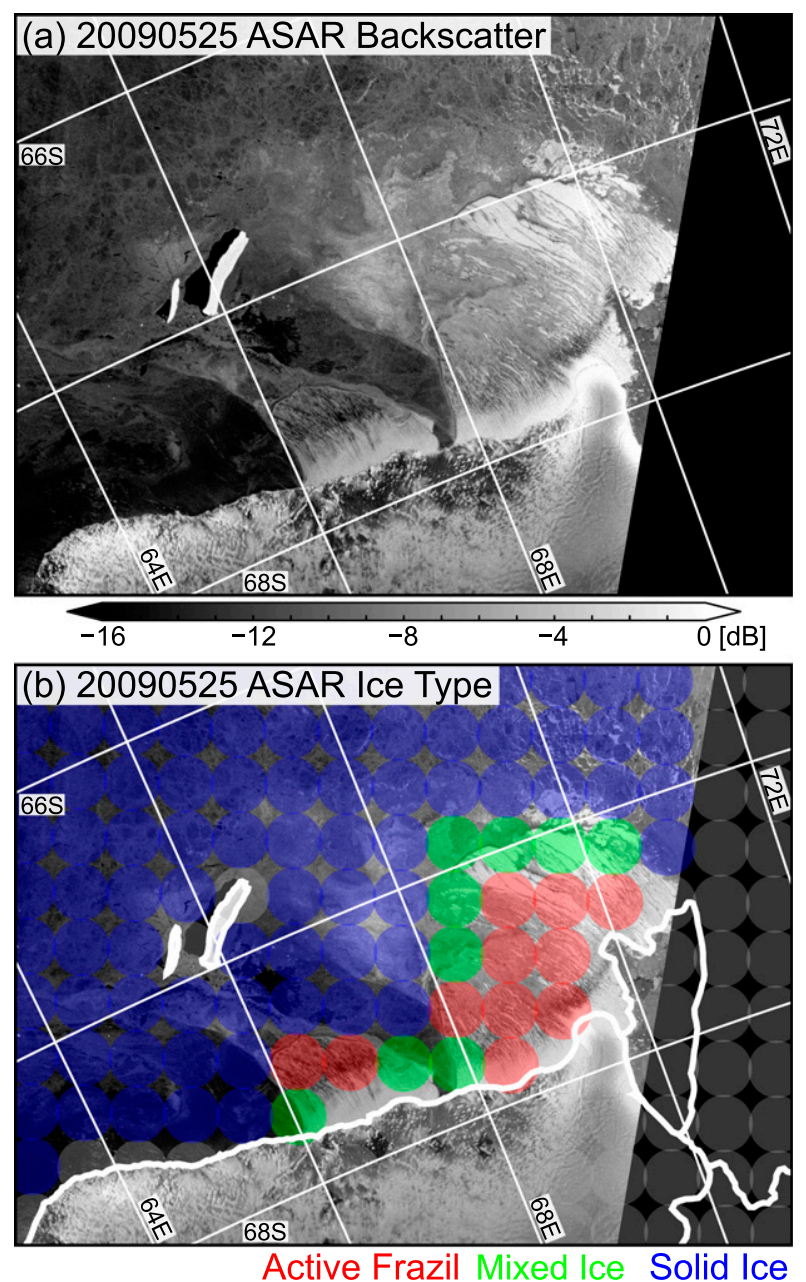

FIG. 3. (a) The backscatter image of ASAR off Cape Darnley on 25 May 2009 and (b) the result of visual classification of ice type on the $25 \mathrm{~km} \times 25 \mathrm{~km}$ EASE-Grid, superimposed on the ASAR image. Active frazil, mixed ice, and solid ice are shown by red, green, and blue colors, respectively.

coastal polynyas. Here, oceanic heat flux from below is expected to be small, and $T_{\mathrm{bttm}}$ is assumed to be at the freezing point of seawater $\left(-1.83^{\circ} \mathrm{C}\right)$. This assumption is based on observations that the temperature of the entire water column is close to the freezing point over the shallow shelf region in the Southern Ocean (Muench and Gordon 1995; Williams and Bindoff 2003), the Arctic Ocean (Weingartner et al. 1998; Martin et al. 2004), and the Sea of Okhotsk (Shcherbina et al. 2003).

For the near-surface atmospheric data, we used air temperature and dewpoint temperature at $2 \mathrm{~m}$, wind speed at $10 \mathrm{~m}$, sea level pressure, and total cloud cover from the fifth generation of ECMWF atmospheric reanalysis of the global climate (ERA5) (Copernicus Climate Change Service 2017) with an hourly interval and a spatial resolution of $0.25^{\circ} \times 0.25^{\circ}$. In this study, heat budget and thermal ice thickness were calculated using atmospheric data with bilinear interpolation at the time of MODIS observation. 

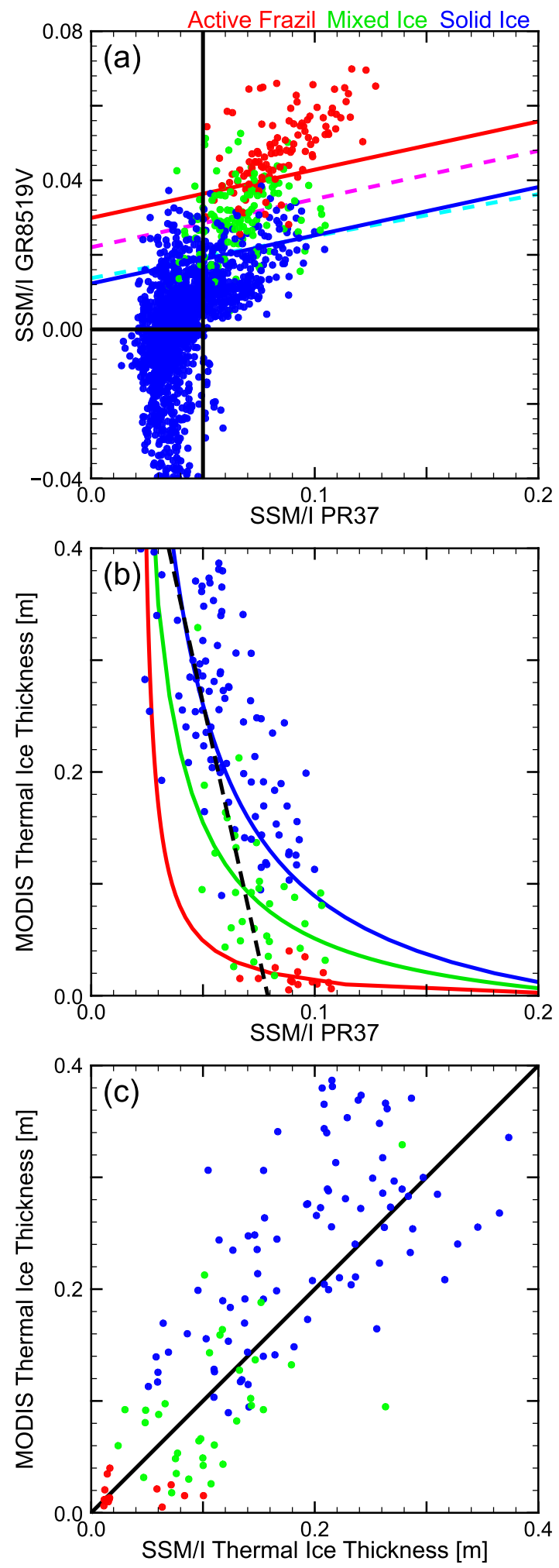

FIG. 4. Scatterplots of (a) SSM/I $\mathrm{PR}_{37}$ vs SSM/I GR $8519 \mathrm{v}$, (b) SSM/I PR 37 vs MODIS thickness, and (c) SSM/I thickness vs MODIS thickness, for the Antarctic coastal polynyas. Active frazil, mixed ice, and solid ice classified from the ASAR images are shown in red, green, and blue, respectively. In (a), the magenta dashed line

\section{c. ASAR images}

We used the backscatter images from ASAR for 22 cases of polynya events formed off the Ross Ice Shelf, off Cape Darnley, and off the Ronne Ice Shelf for comparison data to classify the type of thin sea ice. Table 2 summarizes the location, date, and time of the cases used in this study. Figures 2 and 3 show ASAR backscatter images off the Ross Ice Shelf on 30 April 2009 and off Cape Darnley on 25 May 2009, respectively, with a visual classification of ice type on the $25 \mathrm{~km} \times$ $25 \mathrm{~km}$ EASE-Grid. Based on the backscatter image, pixels with streaks of frazil/grease ice were classified as active frazil, pixels partially with the streaks as mixed ice, and pixels without streaks as solid ice (Figs. 2b and 3b).

\section{Results}

\section{a. Classification of ice type}

Figure 4a shows a scatterplot of SSM/I PR 37 versus $\mathrm{GR}_{8519 \mathrm{~V}}$ (PR-GR plot) for each ice type classified from ASAR images. This plot shows that active frazil and solid ice form separate clusters, and the mixed ice distributes between the two ice types. However, since the mixed ice can be transformed to other ice types within a short time (and vice versa), the correspondence between ice types from ASAR and PR/GR values from SSM/I contains uncertainties caused by the difference in observation time (Table 2). Therefore, the boundaries between active frazil and mixed ice (AF/MX boundary) and between mixed ice and solid ice (MX/SI boundary) remain unclear, and it is difficult to extract the boundaries directly from the PRGR plot.

We used the following procedures to determine the respective boundaries. First, the boundary between active frazil and solid ice (AF/SI boundary) was extracted from the PR-GR plot by using a linear discriminant analysis. Next, the lines parallel to the AF/SI boundary were searched to minimize the classification errors for each ice type. Since regions of $\mathrm{PR}_{37}<$ 0.05 or $\mathrm{GR}_{8519 \mathrm{~V}}<0.00$ on the PR-GR plot are dominated by solid ice (Fig. 4a), the linear discriminant analysis between active frazil and solid ice was performed for the remaining thin ice regions. The result obtained is as follows:

$$
G_{\mathrm{AF} / \mathrm{SI}}=-67.3 \times \mathrm{PR}_{37}+520.2 \times \mathrm{GR}_{8519 \mathrm{~V}}-11.5 .
$$

The line with $G_{\mathrm{AF} / \mathrm{SI}}=0$ (magenta dashed line in Fig. 4a) corresponds to the AF/SI boundary. Although the adopted

indicates the AF/SI boundary obtained from the linear discriminant analysis, the red and blue solid lines indicate the AF/MX and MX/SI boundaries, respectively, and the cyan dashed line indicates the MX/SI boundary obtained by Kashiwase et al. (2019). In (b), the black dashed line indicates the linear PR-thickness relationship obtained by Tamura et al. (2007), the red and blue curves indicate the exponential PR-thickness relationships obtained by Nakata et al. (2019) for active frazil and thin solid ice, respectively, and the green curve indicates the PR-thickness relationship for mixed ice. In (c), the SSM/I thickness is calculated up to $0.4 \mathrm{~m}$ using Eq. (7). 

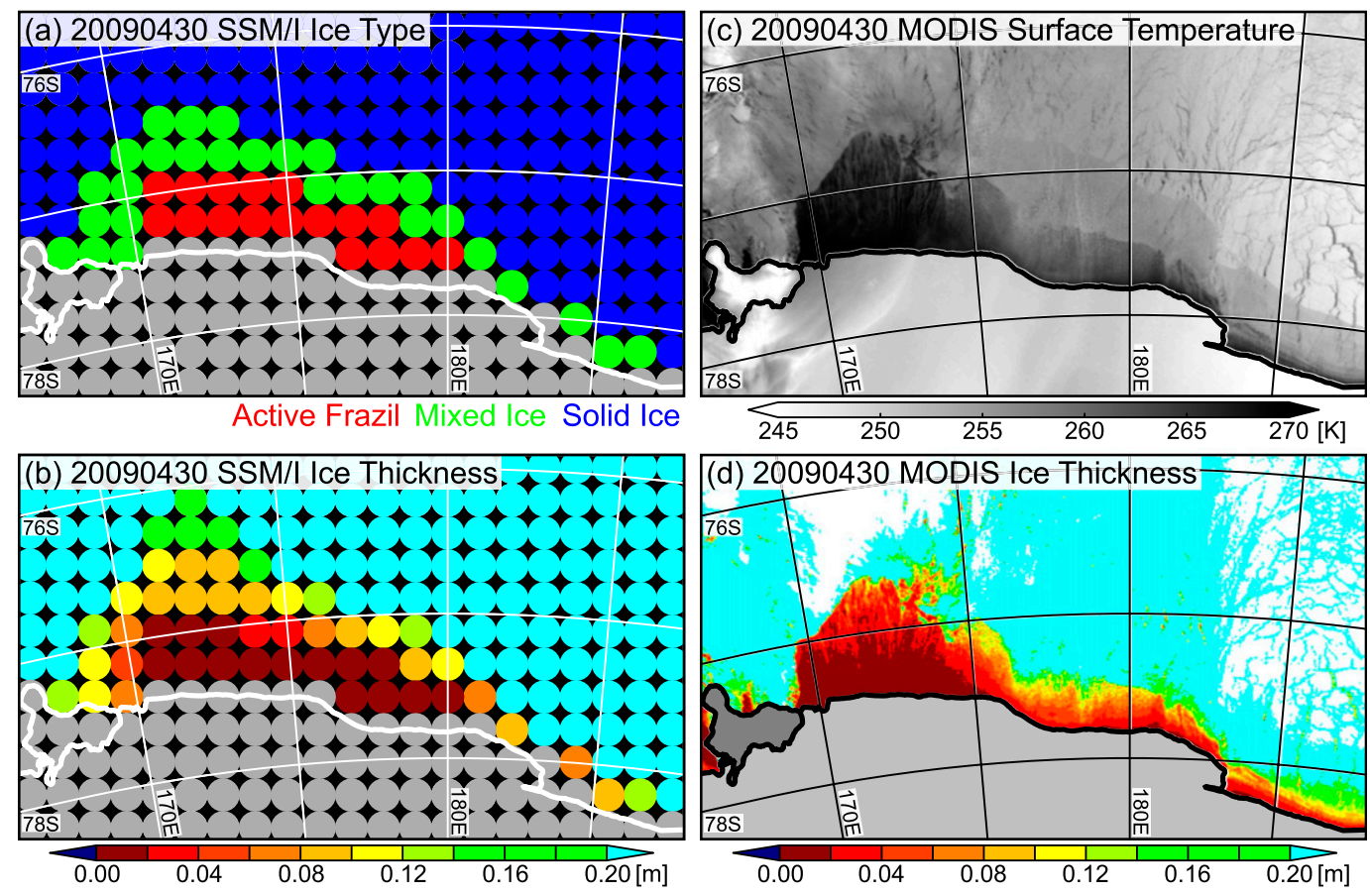

FIG. 5. Spatial distributions of the ice type and thickness off the Ross Ice Shelf on 30 Apr 2009. (a) Ice type from SSM/I, (b) thermal ice thickness from SSM/I, (c) surface temperature from MODIS, and (d) thermal ice thickness from MODIS are shown.

frequencies $\left(\mathrm{GR}_{8936 \mathrm{~V}}: 89\right.$ and $\left.36 \mathrm{GHz}\right)$ are different, a similar line was obtained for the active frazil discrimination in the previous study of AMSR-E (Nakata et al. 2019). The $G_{\mathrm{AF} / \mathrm{SI}}$ values in Eq. (5) were then searched to minimize the classification errors between active frazil and mixed ice and between mixed ice and thin solid ice, thereby the values of 4.1 and -5.1 were determined as the AF/MX and MX/SI boundaries, respectively (red and blue solid lines in Fig. 4a). Notably, the $\mathrm{MX} / \mathrm{SI}$ boundary obtained here is in close agreement with that obtained by Kashiwase et al. (2019) from the mooring observation off Sakhalin in the Sea of Okhotsk (cyan dashed line in Fig. 4a). This suggests that the sea ice type discrimination by our algorithm is valid regardless of the region. When these boundaries are used for discrimination, the SSM/I data correctly classify $80 \%, 63 \%$, and $81 \%$ of active frazil, mixed ice, and thin solid ice pixels, respectively.

\section{b. Estimation of thin ice thickness}

Figure $4 \mathrm{~b}$ shows a scatterplot of SSM/I PR 37 versus MODIS thermal ice thickness (PR-thickness plot). Here, the MODIS thickness is calculated using the averaged surface temperature and conductive heat flux on the $25 \mathrm{~km} \times 25 \mathrm{~km}$ EASE-Grid, and only 11 cases of polynya events with no cloud are plotted (see Table 2). The black dashed line in the plot indicates a linear approximation of the PR-thickness relationship, obtained in the previous SSM/I TIT algorithm for the Antarctic coastal polynyas (Tamura et al. 2007). When the sea ice type is not considered, this linear approximation can roughly represent the relationship between PR value and thermal ice thickness. On the other hand, the red and blue curves in the plot show exponential approximations of PR-thickness relationships for active frazil and thin solid ice, respectively, obtained for the Antarctic coastal polynyas from simultaneous observations of AMSR-E and MODIS (Nakata et al. 2019). These relational expressions are as follows:

$$
\begin{aligned}
& h_{\mathrm{AF}}=\exp \left(\frac{1}{596 \times \mathrm{PR}_{37}-11.8}\right)-1.008, \\
& h_{\mathrm{SI}}=\exp \left(\frac{1}{72 \times \mathrm{PR}_{37}}\right)-1.06
\end{aligned}
$$

where $h_{\mathrm{AF}}$ and $h_{\mathrm{SI}}$ are thicknesses of active frazil and thin solid ice, respectively. Although very thin sea ice, corresponding to $\mathrm{PR}_{37}>0.1$, does not appear probably because of the coarse spatial resolution of SSM/I, the plots from this study are consistent with the exponential approximations of (6) and (7) for active frazil and thin solid ice, respectively. We judged that the exponential relationships obtained from AMSR-E can be applied to SSM/I for the corresponding frequencies. Therefore, instead of conducting a new fitting, we adopted the existing relational expressions of (6) and (7) for estimation of thin ice thickness. The mixed ice thickness, which depends on the degree of mixing of active frazil and thin solid ice, is estimated ad hoc as the intermediate value between the two thicknesses for a corresponding PR value (the green curve in Fig. 4b), following Kashiwase et al. (2019).

Figure 5 shows the spatial distributions of ice type and ice thickness off the Ross Ice Shelf on 30 April 2009, when active frazil was predominant in the polynya. The distribution of ice type from SSM/I (Fig. 5a) agrees well with that from the ASAR 

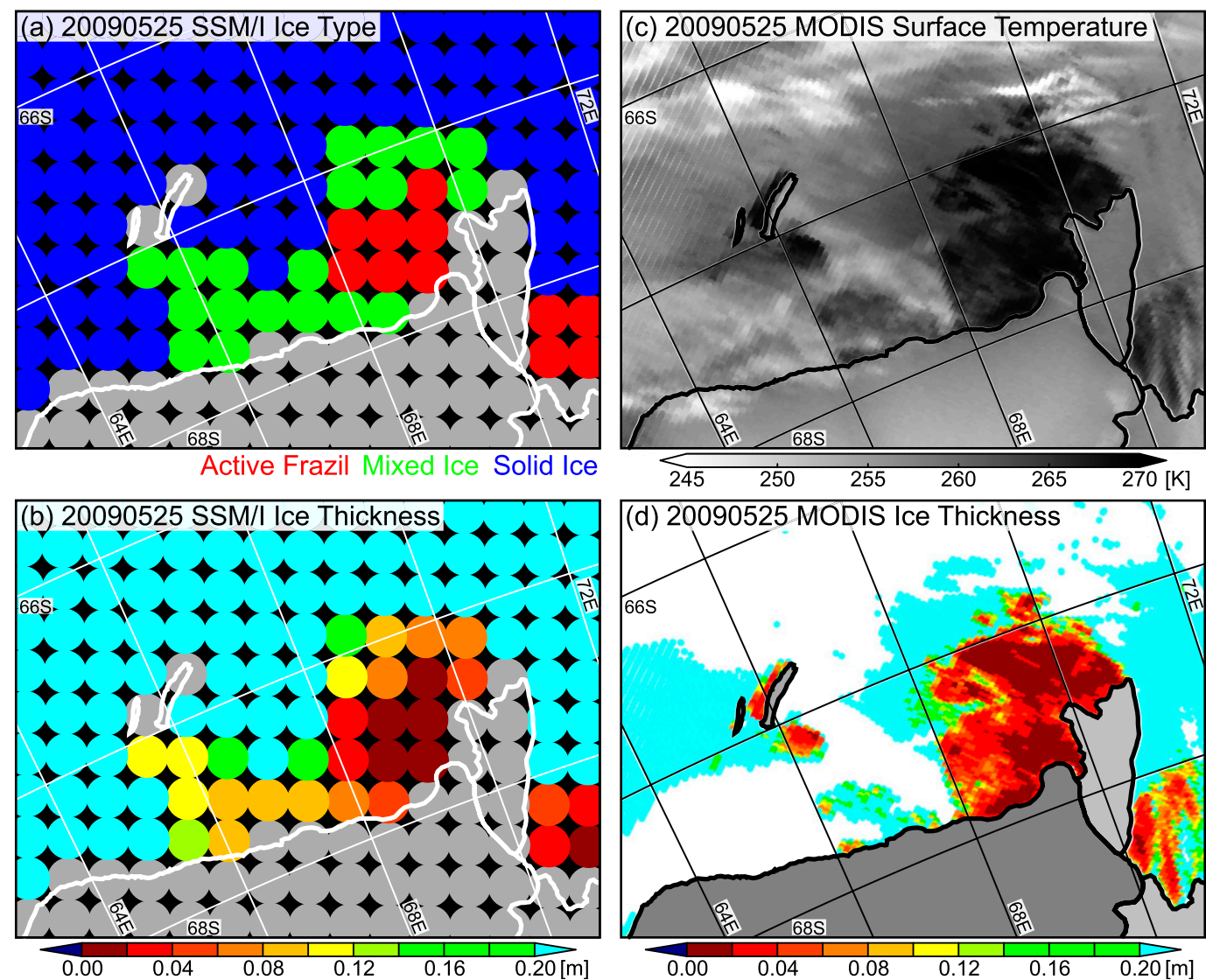

FIG. 6. Spatial distributions of the ice type and thickness off Cape Darnley on 25 May 2009. (a) Ice type from SSM/I, (b) thermal ice thickness from SSM/I, (c) surface temperature from MODIS, and (d) thermal ice thickness from MODIS are shown.

image (Fig. 2b), although the mixed ice region differs slightly due to the difference in observation time between SSM/I and ASAR. The MODIS thermal infrared image (Fig. 5c) shows that the coastal polynya is covered with clouds or ice fog in the region from $173^{\circ} \mathrm{E}$ to $180^{\circ}$. Except for such regions, the SSM/I and MODIS thicknesses (Figs. $5 \mathrm{~b}$ and 5d, respectively) are in good agreement. Figure 6 shows another example of application of the algorithm to the Cape Darnley polynya on 25 May 2009. Also in this case, spatial distributions of ice type and thickness obtained from SSM/I are in good agreement with those obtained from other satellite-based observations (Figs. 3 and 6).

Figure $4 \mathrm{c}$ shows a scatterplot of SSM/I and MODIS thicknesses. Assuming that the MODIS thickness is correct, the error in the SSM/I thickness can be estimated from a comparison of the two ice thicknesses. In the range of $20 \mathrm{~cm}$ or less, the mean bias (SSM/I thickness minus MODIS thickness) is $1.76,1.53$, and $-2.75 \mathrm{~cm}$ and the root-mean-square deviation (RMSD) of the two ice thicknesses is $3.65,4.50$, and $5.15 \mathrm{~cm}$ for active frazil, mixed ice, and thin solid ice, respectively. These results are comparable to previous studies using AMSR-E (Nihashi and Ohshima 2015; Nakata et al. 2019). While there is a room for improvement in the ad hoc assumption for estimating the mixed ice thickness, the present algorithm that accounts for the three ice types can provide the thin ice thickness with reasonable accuracy.

\section{Discussion}

a. Application of the improved TIT algorithm to the AMSR-E

The results of this study from SSM/I are in good agreement with those of previous studies from AMSR-E. The MX/SI boundary obtained in this study nearly coincides with that obtained from the comparison of mooring observation and AMSR-E (Kashiwase et al. 2019). In addition, the PRthickness plot using SSM/I also follows the exponential expressions obtained from AMSR-E for each ice type (Nakata et al. 2019). The spatial resolution of SSM/I is more than 4 times coarser than that of AMSR-E. However, when we use the cases in which active frazil or thin solid ice solely dominates over the pixel, the SSM/I and AMSR-E with different spatial resolutions would show similar characteristics of microwave radiation. This implies that the incorporation of the mixed ice category is also effective as an improvement of the AMSR-E TIT algorithm developed in previous studies.

Figures 7 and 8 show the results of applying the improved algorithm that incorporates the mixed ice category to the 


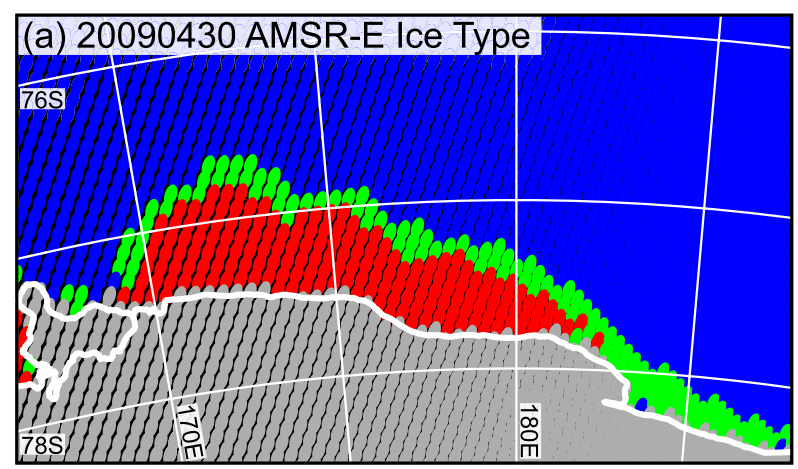

Active Frazil Mixed Ice Solid Ice

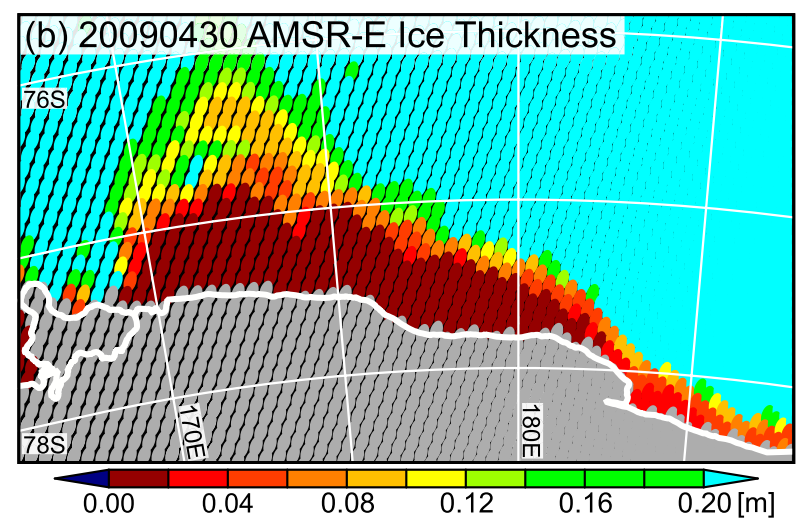

FIG. 7. Spatial distributions of (a) ice type and (b) ice thickness off the Ross Ice Shelf on 30 Apr 2009, derived from AMSR-E. The SSM/I TIT algorithm developed in this study is applied to the AMSR-E data.

AMSR-E/Aqua L2A global swath spatially resampled brightness temperatures, version 4 (Ashcroft and Wentz 2019). In this application, footprints of 19 and $89 \mathrm{GHz}$ channels were matched to those of $36 \mathrm{GHz}$ channel $(8 \mathrm{~km} \times 14 \mathrm{~km})$ by optimal interpolation using the Backus-Gilbert method (Poe 1990; Hunewinkel et al. 1998). The ice type distribution derived from AMSR-E (Figs. 7a and 8a) reproduces well the active frazil region seen in the ASAR image (Figs. 2 and 3), with a smaller mixed ice area than that derived from SSM/I (Figs. 5a and 6a) owing to its finer spatial resolution. The AMSR-E thickness (Figs. $7 \mathrm{~b}$ and $8 \mathrm{~b}$ ) shows a similar spatial distribution to the cloud-free MODIS thickness (Figs. 5d and 6d). Except for the incorporation of the mixed ice category, the thermal ice thickness derived by the improved algorithm is the same as that derived by the previous AMSR-E algorithm (Nakata et al. 2019). When AMSR-E with finer spatial resolution is used, the advantages of incorporating the mixed ice category are relatively small for a larger coastal polynya, while for a smaller coastal polynya, such as that off Ross Island (Fig. 7b), the improved algorithm enables more accurate and detailed estimates of ice type and thickness distributions.

\section{b. Possibility of global application of the improved TIT algorithm}

Previous studies of the AMSR-E algorithm showed that the PR-thickness relationship for thin solid ice is almost the same

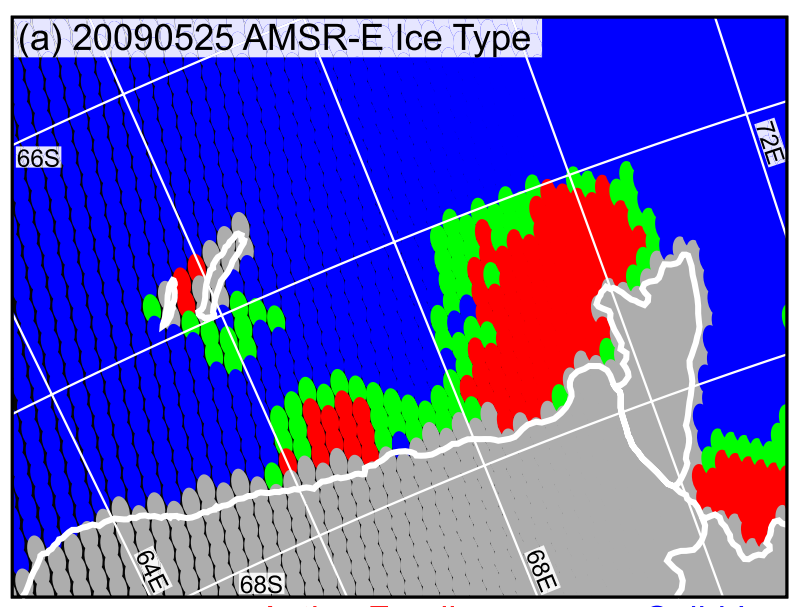

Active Frazil Mixed Ice Solid Ice

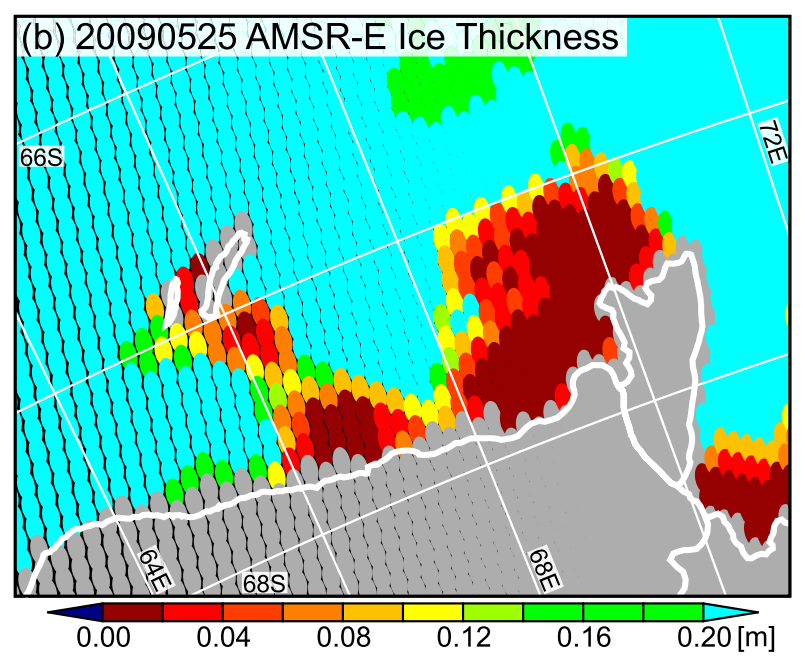

FIG. 8. Spatial distributions of (a) ice type and (b) ice thickness off Cape Darnley on 25 May 2009, derived from AMSR-E. The SSM/I TIT algorithm developed in this study is applied to the AMSR-E data.

between the Southern Ocean (Nakata et al. 2019) and the Sea of Okhotsk (Kashiwase et al. 2019). For active frazil and mixed ice, the PR-thickness relationship obtained from the Antarctic coastal polynyas, which corresponds to Eq. (6) in this study, is also applicable to the region off Sakhalin with reasonable accuracy (Kashiwase et al. 2019). If the PR-thickness relationship for each ice type does not actually depend on region, the TIT algorithm taking account of the ice type can be applied to the global oceans. Here, we discuss the global applicability of the improved algorithm through the validation from 20 cases for the coastal polynya and marginal ice zone in the Chukchi Sea and 6 cases for the coastal polynyas in the Laptev Sea and the North Water, which were used for development and validation of the previous algorithm for the Arctic Ocean (Iwamoto et al. 2013, 2014).

Figure 9 shows the results of a comparison of SSM/I and MODIS on the $25 \mathrm{~km} \times 25 \mathrm{~km}$ EASE-Grid for the Arctic Ocean. Since simultaneous SAR data could not be obtained in 

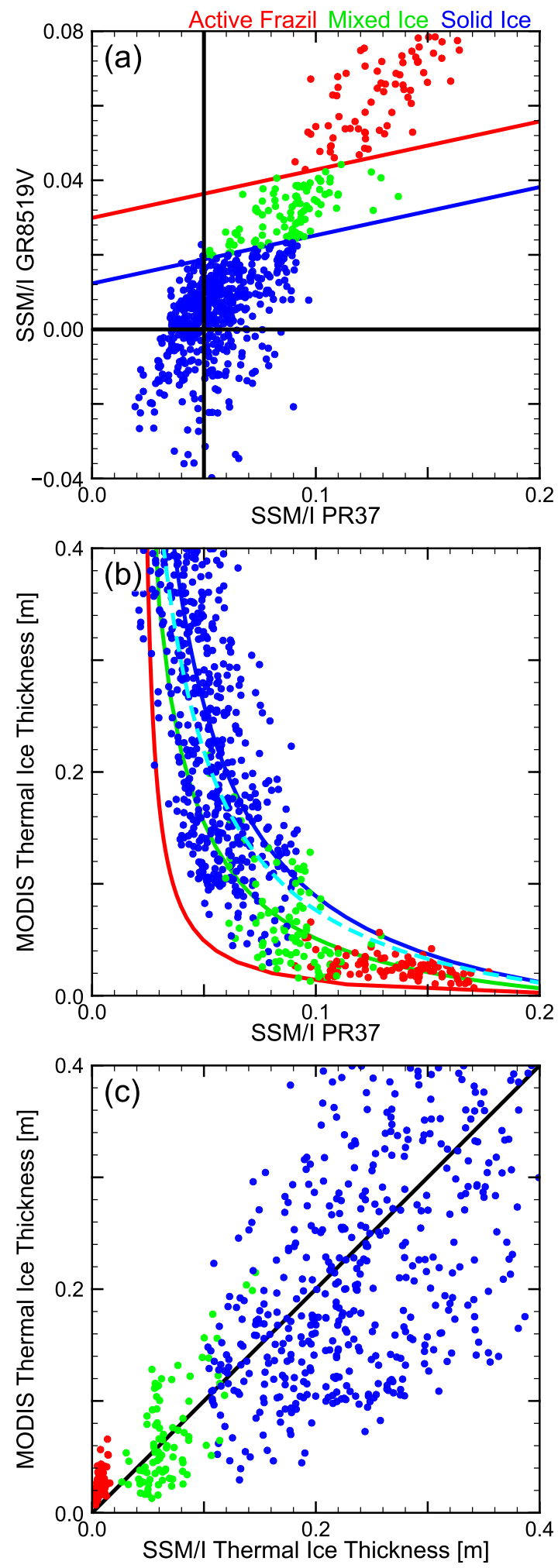

FIG. 9. Scatterplots of (a) SSM/I $\mathrm{PR}_{37}$ vs SSM/I GR $8519 \mathrm{v}$, (b) SSM/I PR 37 vs MODIS thickness, and (c) SSM/I thickness vs MODIS thickness for thin sea ice areas (coastal polynyas and marginal ice zones) in the Arctic Ocean. Active frazil, mixed ice, and thin solid ice classified from the SSM/I algorithm are shown in the Arctic cases, classification of ice type was made using the PR-GR plot of our SSM/I algorithm (Fig. 9a). The PRthickness plot for the Arctic Ocean (Fig. 9b) shows exponential relationships for each ice type that are similar to those obtained from the Antarctic coastal polynyas (the red, green, and blue curves in Fig. 9b). In the Arctic cases, active frazil and mixed ice with very small thicknesses that correspond to PR $>0.1$ can be present, because the case of marginal ice zone is included. This outcome indicates that the use of exponential relationships is much better than that of linear relationships which cannot resolve a very small thickness range. Figure $9 \mathrm{c}$ shows a scatterplot of SSM/I and MODIS thicknesses for the Arctic Ocean. The correspondence between the two thicknesses in the range of $20 \mathrm{~cm}$ or less is comparable to that for the Antarctic coastal polynyas, with the mean bias (SSM/I thickness minus MODIS thickness) of $-1.84,0.09$, and $2.73 \mathrm{~cm}$ and the RMSD of $2.05,3.27$, and $5.37 \mathrm{~cm}$ for active frazil, mixed ice, and thin solid ice, respectively. Therefore, the proposed PRthickness relationships for each ice type likely hold regardless of region, and the improved algorithm that accounts for the three ice types can be a unified algorithm for the global oceans.

\section{c. Uncertainty in the reference ice thickness obtained from MODIS}

In this study, the TIT algorithm was developed using the MODIS thickness as a reference. However, the ambiguity contained in the MODIS thickness itself has a nonnegligible influence on the accuracy of the algorithm. When comparing the MODIS thicknesses between the Southern Ocean and the Arctic Ocean, the thickness of thin solid ice in the Southern Ocean is slightly greater than that in the Arctic Ocean at the same PR value (see Figs. 4 and 9). One possible cause of such regional differences is the underestimation of wind speed over the Antarctic coastal polynyas by ERA5. Compared to observations from automatic weather stations (AWS), the reanalysis data tend to underestimate the wind speed along the Antarctic coastal areas, especially during the katabatic wind events, due to its coarse spatial resolution (e.g., Cullather et al. 1997; Jones et al. 2016; Dong et al. 2020). The underestimated wind speed leads to an underestimation of heat loss from the ocean to the atmosphere, resulting in an overestimation of MODIS thickness. In this subsection, we conduct a heat budget analysis in the Antarctic coastal polynyas using a 1.6-fold enhanced ERA5 wind speed, following a comparison study in the Amundsen Sea (Choi et al. 2019), and discuss the sensitivity of the MODIS thickness to the ERA5 wind speed.

red, green, and blue, respectively. In (a), the red and blue solid lines indicate the AF/MX and MX/SI boundaries, respectively. In (b), the red and blue curves indicate the exponential PR-thickness relationships obtained by Nakata et al. (2019) for active frazil and thin solid ice, respectively, the green curve indicates the PRthickness relationship for mixed ice, and the cyan dashed curve indicates the PR-thickness relationship for thin solid ice obtained from the mooring observation off Sakhalin (Kashiwase et al. 2019). In (c), the SSM/I thickness is calculated up to $0.4 \mathrm{~m}$ using Eq. (7). 

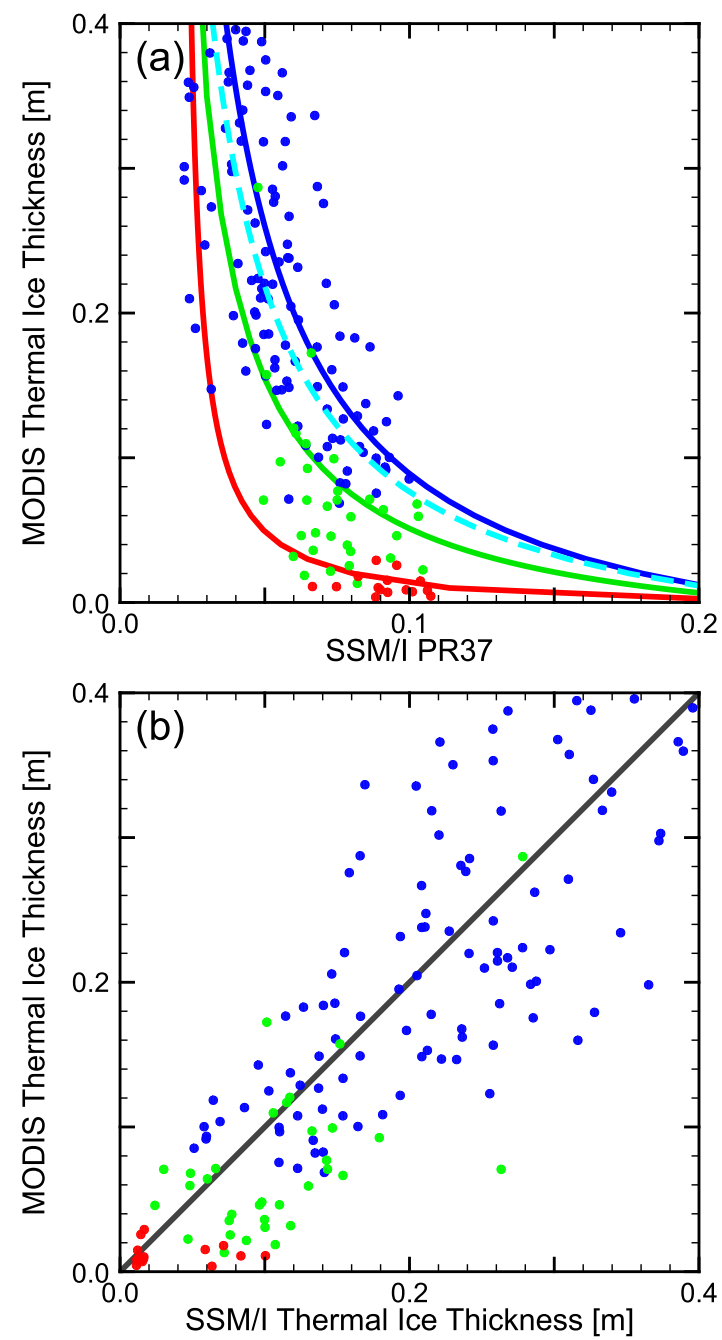

FIG. 10. Scatterplots of (a) SSM/I PR 37 vs MODIS thickness and (b) SSM/I thickness vs MODIS thickness for the Antarctic coastal polynyas when the ERA5 wind speed is enhanced by 1.6 times. Active frazil, mixed ice, and solid ice classified from the ASAR images are shown in red, green, and blue, respectively. In (a), the red and blue curves indicate the exponential PR-thickness relationships obtained by Nakata et al. (2019) for active frazil and thin solid ice, respectively, the green curve indicates the PR-thickness relationship for mixed ice, and the cyan dashed curve indicates the PR-thickness relationship for thin solid ice obtained from the mooring observation off Sakhalin (Kashiwase et al. 2019). In (b), the SSM/I thickness is calculated up to $0.4 \mathrm{~m}$ using Eq. (7).

Figure 10 shows the comparison between SSM/I and windenhanced MODIS thicknesses for the Antarctic coastal polynyas. In the range of $20 \mathrm{~cm}$ or less, the mean bias (SSM/I thickness minus MODIS thickness) of $2.23,3.32$, and $0.34 \mathrm{~cm}$ and the RMSD of $3.84,5.33$, and $4.03 \mathrm{~cm}$ for active frazil, mixed ice, and thin solid ice, respectively. Focusing on the differences in mean biases with and without wind speed enhancement, the results show that wind-enhanced MODIS thicknesses are on average $0.47,1.78$, and $3.09 \mathrm{~cm}$ thinner for active frazil, mixed ice, and thin solid ice, respectively. Therefore, this wind speed enhancement mitigates regional differences in the MODIS thickness, especially in the range of thicker ice (Figs. 9 and 10).

If the MODIS thicknesses in the Southern Ocean are overestimated, Eqs. (6) and (7) defined from these overestimated thicknesses result in overestimated SSM/I thicknesses. On the other hand, Kashiwase et al. (2019) also obtained a PRthickness relationship for thin solid ice from the mooring observation off Sakhalin in the Sea of Okhotsk as follows:

$$
h_{\mathrm{SI}}=\exp \left(\frac{1}{84 \times \mathrm{PR}_{37}}\right)-1.05
$$

The SSM/I thickness from Eq. (8) is smaller than that from Eq. (7); the SSM/I thickness corresponding to $\mathrm{PR}_{37}=0.06$ is $20 \mathrm{~cm}$ in Eq. (7) while $16 \mathrm{~cm}$ in Eq. (8). Such difference is comparable to the reduction in the MODIS thickness by the 1.6-fold wind speed enhancement. This could be interpreted as the difference between the two equations due to the underestimation of ERA5 wind speed in the Southern Ocean. However, exact evaluation on the underestimation of ERA5 wind speed and the overestimation of MODIS thickness in the Southern Ocean requires a direct comparison with in situ observations, such as mooring observations at the Antarctic coastal polynyas.

\section{Concluding remarks}

This study has developed the SSM/I TIT algorithm, which can be a powerful tool to quantify the long-term variations of global sea ice production. First, we classified the type of thin sea ice (active frazil, mixed ice, and thin solid ice) based on the backscatter images from ASAR, and we then compared the $\mathrm{PR} / \mathrm{GR}$ values from SSM/I and the thermal ice thickness from MODIS for each ice type in the Antarctic coastal polynyas. The comparison of SSM/I PR and GR values shows that active frazil and thin solid ice can be clearly distinguished. The comparison between the SSM/I PR value and the MODIS thickness shows the exponential relationships for active frazil and thin solid ice, which are similar to those obtained from the AMSR-E (Nakata et al. 2019). The mixed ice distributes between the two types in both PR-GR and PR-thickness relationships. This study also demonstrates the necessity of incorporating the mixed ice category, which was first proposed by Kashiwase et al. (2019) comparing mooring-based ice thickness with AMSR-E data. Based on these results, we have developed the TIT algorithm that takes account of the three ice types: active frazil, mixed ice, and thin solid ice.

As shown in this study, the microwave characteristics of SSM/I for ice type and thermal ice thickness are in good agreement with those of AMSR-E reported in previous studies (Nakata et al. 2019; Kashiwase et al. 2019). This outcome indicates that proper consideration of ice types allows similar handling of passive microwave radiometer sensors with different spatial resolutions. Incorporation of the mixed ice category is expected to be particularly important for the sensor with coarse spatial resolution. If the mixed ice category is not incorporated, errors in thickness estimation would be large in areas around the boundary between active frazil and thin solid ice. Such errors are critical in the use of SSM/I. However, although the assumed 
PR-thickness relationship for the mixed ice category is ad hoc in this study, the error in the estimation of thermal ice thickness can certainly be reduced. If categorization of thin sea ice into the three ice types is applied to AMSR-E with higher spatial resolution, as proposed in section 4 , more accurate and detailed estimation of thermal ice thickness and thus heat loss/ice production would be possible.

The use of SSM/I provides investigation of long-term variation of thin ice thickness and sea ice production after 1992. However, SSM/I TIT algorithms developed in the past are different from region to region (Tamura et al. 2007; Tamura and Ohshima 2011; Kashiwase et al. 2014), likely owing to the difference in dominant ice type for each region. Therefore, global evaluation of polynya activities and their ice production has been difficult to achieve with the previous TIT algorithms. In this study, we have developed an SSM/I TIT algorithm by considering the three ice types and showed that it is applicable to the global oceans. The uncertainty in the TIT algorithm arise from the referenced MODIS ice thickness caused by ambiguity in the ERA5 wind speed which is likely underestimated around Antarctica. Thus, the incorporation of improved wind speed in the reanalysis data will results in more accurate estimates of global thin ice thickness and hence sea ice production.

Quantifying long-term and global sea ice production based on a unified method could lead to significant advances in understanding the overturning circulation that originates from coastal polynyas. The melting of the Antarctic ice shelves has been reported to have accelerated in recent decades (Silvano et al. 2018; Rignot et al. 2019), and some modeling studies suggest that reduced sea ice production in the Antarctic coastal polynyas accelerates ice shelf melting through the increased inflows of warm Circumpolar Deep Water (Khazendar et al. 2013; Gwyther et al. 2014). The variations in sea ice production in coastal polynyas are closely related to long-term variations in those phenomena that affects the global climate system. Given the accumulation of nearly 30 years of SSM/I data, our TIT algorithm, which can be used to investigate coastal polynyas globally, will be a powerful tool for climate research in various aspects.

Acknowledgments. This work was supported by Grants-inAids for Scientific Research (17H01157, 17H04710, 17H06317, and 20H05707) from the Ministry of Education, Culture, Sports, Science and Technology in Japan. This work was also supported by a research fund for Global Change Observation Mission Water 1 (GCOM-W1) of the Japan Aerospace Exploration Agency (JAXA) (PI RA1W403 and ER2GWF404), National Institute of Polar Research (NIPR) through Project Research KP-303, the Center for the Promotion of Integrated Sciences of SOKENDAI, and the Joint Research Program of the Institute of Low Temperature Science, Hokkaido University.

Data availability statement. The SSM/I and AMSR-E data were provided by the National Snow and Ice Data Center (NSIDC), University of Colorado (https://nsidc.org/). The MODIS data were provided by the Level 1 and Atmosphere Archive and Distribution System (LAADS) Distributed Active Archive Center (DAAC), the Goddard Space Flight Center (https://ladsweb.nascom.nasa.gov/). The ERA5 data were acquired from the Copernicus Climate Change Service Climate Data Store (https://cds.climate.copernicus.eu/cdsapp\#!/home). The ASAR data were provided by the European Space Agency (ESA) (https://earth.esa.int/). The SSM/I thin ice thickness data presented in this study are available from the corresponding author upon reasonable request.

\section{REFERENCES}

Armstrong, R., K. Knowles, M. J. Brodzik, and M. A. Hardman, 1994: DMSP SSM/I-SSMIS Pathfinder daily EASE-Grid brightness temperatures, version 2. NASA National Snow and Ice Data Center Distributed Active Archive Center. Subset used: 1 January 1992-31 December 2018, accessed 17 September 2019, https://doi.org/10.5067/3EX2U1DV3434.

Arndt, J. E., and Coauthors, 2013: The International Bathymetric Chart of the Southern Ocean (IBCSO) version 1.0-A new bathymetric compilation covering circum-Antarctic waters. Geophys. Res. Lett., 40, 3111-3117, https://doi.org/10.1002/ grl.50413.

Ashcroft, P., and F. J. Wentz, 2019: AMSR-E/Aqua L2A global swath spatially-resampled brightness temperatures, version 4. NASA National Snow and Ice Data Center Distributed Active Archive Center. Subset used: 17 May 2006-15 July 2010, accessed 25 March 2020, https://doi.org/10.5067/YL62FUZLAJUT.

Barber, D. G., and R. A. Massom, 2007: The role of sea ice in Arctic and Antarctic polynyas. Polynyas: Windows to the World, $\mathrm{W}$. O. Smith and D. G. Barber, Eds., Elsevier, 1-54, https:// doi.org/10.1016/S0422-9894(06)74001-6.

Cavalieri, D. J., 1994: A microwave technique for mapping thin sea ice. J. Geophys. Res., 99, 12 561-12 572, https://doi.org/10.1029/ 94JC00707.

- , and S. Martin, 1994: The contribution of Alaskan, Siberian, and Canadian coastal polynyas to the cold halocline layer of the Arctic Ocean. J. Geophys. Res., 99, 18343-18362, https:// doi.org/10.1029/94JC01169.

Choi, T., S. J. Kim, J. H. Kim, H. Kwon, and M. A. Lazzara, 2019: Characteristics of surface meteorology at Lindsey Islands, Amundsen Sea, West Antarctica. J. Geophys. Res. Atmos., 124, 6294-6306, https://doi.org/10.1029/2018JD029556.

Comiso, J. C., R. Kwok, S. Martin, and A. L. Gordon, 2011: Variability and trends in sea ice extent and ice production in the Ross Sea. J. Geophys. Res., 116, C04021, https://doi.org/ 10.1029/2010JC006391.

Copernicus Climate Change Service, 2017: ERA5: Fifth generation of ECMWF atmospheric reanalyses of the global climate. Copernicus Climate Change Service Climate Data Store, accessed 30 April 2020, https://cds.climate.copernicus.eu/ cdsapp\#!/home.

Cox, G. F. N., and W. F. Weeks, 1974: Salinity variations in sea ice. J. Glaciol., 13, 109-120, https://doi.org/10.1017/ S0022143000023418.

Cullather, R. I., D. H. Bromwich, and R. W. Grumbine, 1997: Validation of operational numerical analyses in Antarctic latitudes. J. Geophys. Res., 102, 13 761-13 784, https://doi.org/ 10.1029/96JD03328.

Dong, X., Y. Wang, S. Hou, M. Ding, B. Yin, and Y. Zhang, 2020: Robustness of the recent global atmospheric reanalyses for Antarctic near-surface wind speed climatology. J. Climate, 33, 4027-4043, https://doi.org/10.1175/JCLI-D-19-0648.1.

Drucker, R., S. Martin, and R. Moritz, 2003: Observations of ice thickness and frazil ice in the St. Lawrence Island polynya 
from satellite imagery, upward looking sonar, and salinity/ temperature moorings. J. Geophys. Res., 108, 3149, https:// doi.org/10.1029/2001JC001213.

Fukamachi, Y., D. Simizu, K. I. Ohshima, H. Eicken, A. R. Mahoney, K. Iwamoto, E. Moriya, and S. Nihashi, 2017: Seaice thickness in the coastal northeastern Chukchi Sea from moored ice-profiling sonar. J. Glaciol., 63, 888-898, https:// doi.org/10.1017/jog.2017.56.

Grenfell, T., and J. Comiso, 1986: Multifrequency passive microwave observations of first-year sea ice grown in a tank. IEEE Trans. Geosci. Remote Sens., GE-24, 826-831, https://doi.org/ 10.1109/TGRS.1986.289696.

Gwyther, D. E., B. K. Galton-Fenzi, J. R. Hunter, and J. L. Roberts, 2014: Simulated melt rates for the Totten and Dalton ice shelves. Ocean Sci., 10, 267-279, https://doi.org/10.5194/os-10-267-2014.

Hunewinkel, T., T. Markus, and G. Heygster, 1998: Improved determination of the sea ice edge with SSM/I data for small-scale analyses. IEEE Trans. Geosci. Remote Sens., 36, 1795-1808, https://doi.org/10.1109/36.718647.

Hwang, B. J., J. K. Ehn, D. G. Barber, R. Galley, and T. C. Grenfell, 2007: Investigations of newly formed sea ice in the Cape Bathurst polynya: 2. Microwave emission. J. Geophys. Res., 112, C05003, https://doi.org/10.1029/2006JC003703.

Iwamoto, K., K. I. Ohshima, T. Tamura, and S. Nihashi, 2013: Estimation of thin ice thickness from AMSR-E data in the Chukchi Sea. Int. J. Remote Sens., 34, 468-489, https://doi.org/ 10.1080/01431161.2012.712229.

,-- , and -2014 : Improved mapping of sea ice production in the Arctic Ocean using AMSR-E thin ice thickness algorithm. J. Geophys. Res. Oceans, 119, 3574-3594, https:// doi.org/10.1002/2013JC009749.

Jones, R. W., I. A. Renfrew, A. Orr, B. G. M. Webber, D. M. Holland, and M. A. Lazzara, 2016: Evaluation of four global reanalysis products using in situ observations in the Amundsen Sea Embayment, Antarctica. J. Geophys. Res. Atmos., 121, 6240-6257, https://doi.org/10.1002/2015JD024680.

Kashiwase, H., K. I. Ohshima, and S. Nihashi, 2014: Long-term variation in sea ice production and its relation to the intermediate water in the Sea of Okhotsk. Prog. Oceanogr., 126, 21-32, https://doi.org/10.1016/j.pocean.2014.05.004.

—_- — Y. Fukamachi, S. Nihashi, and T. Tamura, 2019: Evaluation of AMSR-E thin ice thickness algorithm from a mooring-based observation: How can the satellite observe a sea ice field with nonuniform thickness distribution? J. Atmos. Oceanic Technol., 36, 1623-1641, https://doi.org/ 10.1175/JTECH-D-18-0218.1.

Key, J. R., J. B. Collins, C. Fowler, and R. S. Stone, 1997: Highlatitude surface temperature estimates from thermal satellite data. Remote Sens. Environ., 61, 302-309, https://doi.org/ 10.1016/S0034-4257(97)89497-7.

Khazendar, A., M. P. Schodlok, I. Fenty, S. R. M. Ligtenberg, E. Rignot, and M. R. van den Broeke, 2013: Observed thinning of Totten Glacier is linked to coastal polynya variability. Nat. Commun., 4, 2857, https://doi.org/10.1038/ncomms3857.

Kimura, N., and M. Wakatsuchi, 1999: Processes controlling the advance and retreat of sea ice in the Sea of Okhotsk. J. Geophys. Res., 104, 11 137-11 150, https://doi.org/10.1029/1999JC900004.

Knowles, K., M. Savoie, R. Armstrong, and M. J. Brodzik, 2006: AMSR-E/Aqua daily EASE-Grid brightness temperatures, version 1. NASA National Snow and Ice Data Center Distributed Active Archive Center. Subset used: 19 June 2002-27 September 2011, accessed 20 August 2019, https:// doi.org/10.5067/XIMNXRTQVMOX.
Kondo, J., 1975: Air-sea bulk transfer coefficients in diabatic conditions. Bound.-Layer Meteor., 9, 91-112, https://doi.org/ 10.1007/BF00232256.

König-Langlo, G., and E. Augstein, 1994: Parameterization of the downward long-wave radiation at the Earth's surface in polar regions. Meteor. Z., 3, 343-347.

Lüpkes, C., and V. M. Gryanik, 2015: A stability-dependent parametrization of transfer coefficients for momentum and heat over polar sea ice to be used in climate models. J. Geophys. Res. Atmos., 120, 552-581, https://doi.org/10.1002/2014JD022418.

Martin, S., R. Drucker, and K. Yamashita, 1998: The production of ice and dense shelf water in the Okhotsk Sea polynyas. J. Geophys. Res., 103, 27 771-27 782, https://doi.org/10.1029/ 98JC02242.

—_ — - R. Kwok, and B. Holt, 2004: Estimation of the thin ice thickness and heat flux for the Chukchi Sea Alaskan coast polynya from Special Sensor Microwave/Imager data, 1990-2001. J. Geophys. Res., 109, C10012, https://doi.org/ 10.1029/2004JC002428.

Maykut, G. A., 1978: Energy exchange over young sea ice in the central Arctic. J. Geophys. Res., 83, 3646-3658, https://doi.org/ 10.1029/JC083iC07p03646.

— , and D. K. Perovich, 1987: The role of shortwave radiation in the summer decay of a sea ice cover. J. Geophys. Res., 92, 7032, https://doi.org/10.1029/JC092iC07p07032.

MODIS Characterization Support Team, 2017a: MODIS 1km calibrated radiances product. NASA MODIS Adaptive Processing System, Goddard Space Flight Center. Subset used: 12 December 2004-15 July 2010, accessed 22 April 2019, https://doi.org/10.5067/ MODIS/MOD021KM.061.

- 2017b: MODIS $1 \mathrm{~km}$ calibrated radiances product. NASA MODIS Adaptive Processing System, Goddard Space Flight Center. Subset used: 12 December 2004-15 July 2010, accessed 22 April 2019, https://doi.org/10.5067/MODIS/MYD021KM.061.

Morales Maqueda, M. A., A. J. Willmott, and N. R. T. Biggs, 2004: Polynya dynamics: A review of observations and modeling. Rev. Geophys., 42, RG1004, https://doi.org/10.1029/2002RG000116.

Muench, R. D., and A. L. Gordon, 1995: Circulation and transport of water along the western Weddell Sea margin. J. Geophys. Res., 100, 18 503-18 515, https://doi.org/10.1029/95JC00965.

Nakanowatari, T., K. I. Ohshima, and M. Wakatsuchi, 2007: Warming and oxygen decrease of intermediate water in the northwestern North Pacific, originating from the Sea of Okhotsk, 1955-2004. Geophys. Res. Lett., 34, L04602, https:// doi.org/10.1029/2006GL028243.

Nakata, K., K. I. Ohshima, and S. Nihashi, 2019: Estimation of thinice thickness and discrimination of ice type from AMSR-E passive microwave data. IEEE Trans. Geosci. Remote Sens., 57, 263-276, https://doi.org/10.1109/TGRS.2018.2853590.

Naoki, K., J. Ukita, F. Nishio, M. Nakayama, J. C. Comiso, and A. Gasiewski, 2008: Thin sea ice thickness as inferred from passive microwave and in situ observations. J. Geophys. Res., 113, C02S16, https://doi.org/10.1029/2007JC004270.

Nihashi, S., and K. I. Ohshima, 2015: Circumpolar mapping of Antarctic coastal polynyas and landfast sea ice: Relationship and variability. J. Climate, 28, 3650-3670, https://doi.org/ 10.1175/JCLI-D-14-00369.1.

- - - T. Tamura, Y. Fukamachi, and S. Saitoh, 2009: Thickness and production of sea ice in the Okhotsk Sea coastal polynyas from AMSR-E. J. Geophys. Res., 114, C10025, https://doi.org/10.1029/2008JC005222.

,$- \ldots$, and $\longrightarrow$, 2017: Sea-ice production in Antarctic coastal polynyas estimated from AMSR2 data and its validation using 
AMSR-E and SSM/I-SSMIS data. IEEE J. Sel. Top. Appl. Earth Obs. Remote Sens., 10, 3912-3922, https://doi.org/ 10.1109/JSTARS.2017.2731995.

Ohshima, K. I., T. Watanabe, and S. Nihashi, 2003: Surface heat budget of the Sea of Okhotsk during 1987-2001 and the role of sea ice on it. J. Meteor. Soc. Japan, 81, 653-677, https://doi.org/ 10.2151/jmsj.81.653.

- and Coauthors, 2013: Antarctic Bottom Water production by intense sea-ice formation in the Cape Darnley polynya. Nat. Geosci., 6, 235-240, https://doi.org/10.1038/ngeo1738.

- , N. Tamaru, H. Kashiwase, S. Nihashi, K. Nakata, and K. Iwamoto, 2020: Estimation of sea ice production in the Bering Sea from AMSR-E and AMSR2 data, with special emphasis on the Anadyr polynya. J. Geophys. Res. Oceans, 125, e2019JC016023, https://doi.org/10.1029/2019JC016023.

Orsi, A. H., G. C. Johnson, and J. L. Bullister, 1999: Circulation, mixing and production of Antarctic Bottom Water. Prog. Oceanogr., 43, 55-109, https://doi.org/10.1016/S0079-6611(99) 00004-X.

Paul, S., S. Willmes, and G. Heinemann, 2015: Long-term coastalpolynya dynamics in the southern Weddell Sea from MODIS thermal-infrared imagery. Cryosphere, 9, 2027-2041, https:// doi.org/10.5194/tc-9-2027-2015.

Poe, G. A., 1990: Optimum interpolation of imaging microwave radiometer data. IEEE Trans. Geosci. Remote Sens., 28, 800-810, https://doi.org/10.1109/36.58966.

Preußer, A., G. Heinemann, S. Willmes, and S. Paul, 2016: Circumpolar polynya regions and ice production in the Arctic: Results from MODIS thermal infrared imagery from 2002/2003 to 2014/2015 with a regional focus on the Laptev Sea. Cryosphere, 10, 3021-3042, https://doi.org/10.5194/tc-10-3021-2016.

_ , K. I. Ohshima, K. Iwamoto, S. Willmes, and G. Heinemann, 2019: Retrieval of wintertime sea ice production in Arctic polynyas using thermal infrared and passive microwave remote sensing data. J. Geophys. Res. Oceans, 124, 5503-5528, https://doi.org/10.1029/2019JC014976.

Purkey, S. G., and G. C. Johnson, 2013: Antarctic Bottom Water warming and freshening: Contributions to sea level rise, ocean freshwater budgets, and global heat gain. J. Climate, 26, 6105-6122, https://doi.org/10.1175/JCLI-D-12-00834.1.

Rhein, M., and Coauthors, 2013: Observations ocean. Climate Change 2013: The Physical Science Basis, T. F. Stocker et al., Eds., Cambridge University Press, 255-297.

Rignot, E., J. Mouginot, B. Scheuchl, M. Van Den Broeke, M. J. Van Wessem, and M. Morlighem, 2019: Four decades of Antarctic ice sheet mass balance from 1979-2017. Proc. Natl. Acad. Sci. USA, 116, 1095-1103, https://doi.org/10.1073/ pnas.1812883116.

Shcherbina, A. Y., L. D. Talley, and D. L. Rudnick, 2003: Direct observations of North Pacific ventilation: Brine rejection in the Okhotsk Sea. Science, 302, 1952-1955, https://doi.org/ 10.1126/science.1088692.

Silvano, A., S. R. Rintoul, B. Peña-Molino, W. R. Hobbs, E. van Wijk, S. Aoki, T. Tamura, and G. D. Williams, 2018: Freshening by glacial meltwater enhances melting of ice shelves and reduces formation of Antarctic Bottom Water. Sci. Adv., 4, eaap9467, https://doi.org/10.1126/sciadv.aap9467.

Steffen, K., 1991: Energy flux density estimation over sea ice based on satellite passive microwave measurements. Ann. Glaciol., 15, 178-183, https://doi.org/10.3189/1991AoG15-1-178-183.

__ and J. A. Maslanik, 1988: Comparison of Nimbus 7 scanning multichannel microwave radiometer radiances and derived sea ice concentrations with Landsat imagery for the North Water area of Baffin Bay. J. Geophys. Res., 93, 10 769-10 781, https://doi.org/10.1029/JC093iC09p10769.

Tamura, T., and K. I. Ohshima, 2011: Mapping of sea ice production in the Arctic coastal polynyas. J. Geophys. Res., 116, C07030, https://doi.org/10.1029/2010JC006586.

, _ - T. Markus, D. J. Cavalieri, S. Nihashi, and N. Hirasawa, 2007: Estimation of thin ice thickness and detection of fast ice from SSM/I data in the Antarctic Ocean. J. Atmos. Oceanic Technol., 24, 1757-1772, https://doi.org/10.1175/JTECH2113.1.

- _ _ and S. Nihashi, 2008: Mapping of sea ice production for Antarctic coastal polynyas. Geophys. Res. Lett., 35, L07606, https://doi.org/10.1029/2007GL032903.

$\longrightarrow,-$, A. D. Fraser, and G. D. Williams, 2016: Sea ice production variability in Antarctic coastal polynyas. J. Geophys. Res. Oceans, 121, 2967-2979, https://doi.org/10.1002/2015JC011537.

Tateyama, K., H. Enomoto, S. Takahashi, K. Shirasaki, K. Hyakutake, and F. Nishio, 2000: New passive microwave remote sensing technique for sea ice in the Sea of Okhotsk using $85-\mathrm{GHz}$ channel of DMSP SSM/I. Bull. Glaciol. Res., 17, 23-30.

_, — , T. Toyota, and S. Uto, 2002: Sea ice thickness estimated from passive microwave radiometers. Polar Meteor. Glaciol., 16, 15-31.

Warner, M. J., J. L. Bullister, D. P. Wisegarver, R. H. Gammon, and R. F. Weiss, 1996: Basin-wide distributions of chlorofluorocarbons CFC-11 and CFC-12 in the North Pacific: 1985-1989. J. Geophys. Res., 101, 20 525-20 542, https://doi.org/10.1029/ 96JC01849.

Weingartner, T. J., D. J. Cavalieri, K. Aagaard, and Y. Sasaki, 1998: Circulation, dense water formation, and outflow on the northeast Chukchi Shelf. J. Geophys. Res., 103, 7647-7661, https://doi.org/10.1029/98JC00374.

Williams, G. D., and N. L. Bindoff, 2003: Wintertime oceanography of the Adélie depression. Deep-Sea Res. II, 50, 1373-1392, https://doi.org/10.1016/S0967-0645(03)00074-2.

Yu, Y., and D. A. Rothrock, 1996: Thin ice thickness from satellite thermal imagery. J. Geophys. Res., 101, 25 753-25 766, https:// doi.org/10.1029/96JC02242. 